\section{REDE URBANA, POLICENTRISMO E FLUXOS DE GESTÃO PÚBLICA DO TERRITÓRIO NA REGIÃO DOS VALES - RS}

\author{
FACCIN, C. R.1; GIACOMETTI, N. B. DE.1; SILVEIRA, R. L. L.; BRANDT, G. B.³
}

PALAVRAS CHAVE: Gestão do Território. Rede Urbana. Cidade Média. Fluxos de Gestão Pública. Região dos Vales.

\section{RESUMO}

A identificação e análise dos fluxos de gestão do território tornam-se importantes, pois permitem analisar o conteúdo policêntrico na dinâmica urbana regional e suas influências na rede urbana. Assim, objetiva-se analisar os fluxos de gestão pública federal e estadual presentes na Região dos Vales, localizada na área central do estado do Rio Grande do Sul, com destaque para as cidades médias de Santa Cruz do Sul e Lajeado. Inicialmente foi feita uma revisão bibliográfica para delimitar os principais conceitos que orientam o estudo e, após, foram sistematizados dados secundários a partir das bases da REGIC (2007), Censo Demográfico (2010) e Gestão do Território (2014), levantadas pelo IBGE. Os resultados preliminares dão destaque para a condição de comando e de gestão territorial que as cidades de Lajeado e de Santa Cruz do Sul exercem em suas regiões imediatas de influência, respectivamente, o Vale do Taquari e o Vale do Rio Pardo, e no conjunto do território da região dos Vales, através dos fluxos de gestão pública decorrentes da descentralização dos serviços públicos estaduais e federais. Como resultado dessa condição, destaca-se também o expressivo grau de centralidade urbana de Santa Cruz do Sul e Lajeado no âmbito da rede urbana regional e em relação aos demais municípios da região.

\section{URBAN NETWORK, POLICENTRISM AND TERRITORY MANAGEMENT FLOWS IN REGIÃO DOS VALES - RS}

KEYWORDS: Territory Management. Urban Network. Territory Management Flows. Medium-sized City. Região dos Vales.

\begin{abstract}
The identification and analysis of the territorial management flows become important, since they allow the analysis of the polycentric content in the regional urban dynamics and its influences in the urban network. Therefore, the objective is to analyze the state and federal public management flows present in the Região dos Vales, located in the central area of the state of Rio Grande do Sul, with emphasis on the medium-sized cities of Santa Cruz do Sul and Lajeado. Initially a bibliographic review was done to delimit the main concepts that guide the study and, afterwards, secondary data were systematized from the bases of REGIC (2007), Demographic Census (2010) and Territory Management (2014), collected by IBGE. The preliminary results highlight the condition of command and territorial management that the cities of Lajeado and Santa Cruz do Sul exert in their immediate regions of influence, respectively, the Vale do Taquari and the Vale do Rio Pardo, and in the joint of the Região dos Vales, through public management flows resulting from the decentralization of state and federal public services. As a result of this condition, we also highlight the expressive degree of urban centrality of Santa Cruz do Sul and Lajeado within the regional urban network and in relation to the other municipalities in the region.
\end{abstract}

\footnotetext{
${ }^{1}$ Acadêmicos do curso de Arquitetura na Universidade de Santa Cruz do Sul.

2 Docente do Departamento de História e Geografia na Universidade de Santa Cruz do Sul.

${ }^{3}$ Docente do Departamento de Comunicação Social na Universidade de Santa Cruz do Sul.
} 


\section{INTRODUÇÃO}

Os estudos sobre as redes urbanas têm avançado por diversas áreas do conhecimento, notadamente no campo das ciências sociais, onde atualmente tem ganhado destaque a abordagem sobre o papel desempenhado pelas cidades médias nas redes urbanas e em suas áreas ou regiões de influência. A análise dessa categoria de centro urbano tornou-se imprescindível, já que tais cidades são determinantes no atual processo de desconcentração da economia brasileira. Logo, é necessário entender o papel que as cidades médias desempenham em suas áreas de influência (RAMOS, MATOS e GARCIA, 2011). Além disso, as redes urbanas têm assumido crescente importância, uma vez que elas se têm perfilado como um novo paradigma para a organização urbana, como instrumento para estimular a posição competitiva das cidades e como forma de resolver problemas específicos (FONSECA e RAMOS, 2011).

No contexto das redes urbanas que integram, as cidades médias articulam circulação, distribuição e consumo e materializam o sistema de produção. Além disso, consolidam a condição de comando e cristalizam o sistema de decisão e gestão, por meio da localização seletiva de órgãos da administração pública e sedes de grandes corporações, oferecendo um nítido posicionamento hierarquizado dos centros. (MOURA e WERNECK, 2001).

Tendo isso em vista, o presente estudo aborda a distribuição espacial das estruturas de gestão do território, em relação aos fluxos de gestão pública federal entre os municípios da Região dos Vales e à quantidade de centros de gestão pública estadual presentes na região. A Região dos Vales é definida como aquela que espacialmente engloba conjuntamente os espaços geográficos regionais correspondentes às delimitações políticas dos COREDEs do Vale do Rio Pardo e do Taquari. Também se analisa, de modo preliminar, como ocorre o processo de gestão do território regional pelas cidades médias de Santa Cruz do Sul e Lajeado, que se relacionam com e influenciam, respectivamente, as regiões do Vale do Rio Pardo e o Vale do Taquari. Foram analisadas as influências e capacidade de gestão das duas cidades na configuração da rede urbana e a possível existência de um conteúdo policêntrico na dinâmica urbana regional. Para isso, foram utilizados dados dos seguintes estudos: Centros de Gestão do Território (2014), Região de Influência das Cidades (REGIC) (2007) e Censo Demográfico (2010), realizados pelo IBGE.

Este artigo apresenta alguns dos resultados iniciais do projeto de pesquisa "Cidades Médias, Policentrismo e Desenvolvimento Regional na Região dos Vales-RS: Uma análise do papel da rede urbana nos processos de coesão e desenvolvimento territorial”, desenvolvido pelo GEPEUR - Grupo de Pesquisa Estudos Urbanos e Regionais, sendo este vinculado ao Programa de Pós-Graduação em Desenvolvimento Regional da Universidade de Santa Cruz do Sul (UNISC).

Após um tópico inicial com a contextualização teórica, sobre os conceitos de policentrismo, rede urbana e cidade média, e de um segundo tópico dedicado à metodologia utilizada na pesquisa, os resultados parciais já obtidos serão apresentados divididos em três subtópicos. Primeiramente a caracterização da Região dos Vales, seguida de uma breve análise acerca das emancipações e mudanças na estrutura territorial da região ao longo dos anos. Por fim, apresentamos a análise dos dados referentes aos centros públicos de gestão do território em instância federal e estadual existentes nessas cidades, e aos seus fluxos de gestão que circulam pelo território da região dos Vales. Ao final, encerraremos este artigo com as considerações finais.

\section{FUNDAMENTAÇÃO TEÓRICA}

\subsection{POLICENTRISMO}

O interesse pelas regiões urbanas policêntricas aumentou rapidamente durante a última década. Isso pode ser parcialmente explicado pela crença emergente de que as regiões em geral estão se tornando o nível espacial mais importante da competição territorial internacional (MEIJERS, 2005). Além disso, as dimensões do conceito de policentrismo têm fundamentado grande parte das atuais políticas de ordenamento do território europeu, 
sendo apresentado e discutido com uma das respostas possíveis para a resolução dos desequilíbrios regionais (CARMO, 2008).

A noção de região urbana policêntrica é frequentemente definida como um conjunto de cidades historicamente distintas, administrativa e politicamente separadas, em proximidade razoável entre si e com alto grau de interconexões e complementaridades funcionais (KLOOSTERMAN e LAMBREGTS, 2001; DAVOUDI 2007). Em uma região policêntrica, não é apenas uma cidade que oferece uma gama completa de funções econômicas, amenidades urbanas ou ambientes residenciais e de trabalho, mas sim todo o sistema de cidades dentro de uma região. Nela, cada cidade desempenha um papel distinto e especializado e presta serviços especializados, para os habitantes e empresas das cidades e áreas rurais constituintes da região. (MEIJERS, 2006)

Carmo (2008, p. 790) também afirma que a eficácia do modelo policêntrico, no contexto da União Europeia, se deve, em parte, pela simplicidade de seus eixos orientadores:

(...) desenvolver entre as cidades mais dinâmicas de âmbito regional um conjunto de redes e de fluxos capazes de incrementar formas sustentáveis de complementaridade e de cooperação funcional no sentido de equilibrar as oportunidades de desenvolvimento econômico e regional.

No entanto, o conceito de policentrismo, em nível regional, ainda está em fase de desenvolvimento. Seu conceito não é consensual e tem sido objeto de múltiplas interpretações (CAÑIZARES, 2007; FONSECA e RAMOS, 2011). Sua definição, por exemplo, é problemática em pelo menos dois sentidos: Qual seria uma proximidade razoável entre as cidades? E como medir a interconexão funcional? No que diz respeito à proximidade, no relatório da ESPON (2004) foi utilizado o tempo de trânsito de no máximo 45 minutos para medir uma distância razoável na qual as pessoas estão preparadas para viajar diariamente. Já no que diz respeito à interconexão funcional, o critério comum é a jornada de viagem para trabalho, mas isso ignora outras atividades de geração de viagem, como compras, lazer, fluxos de bens e informações entre empresas (DAVOUDI, 2007).

A ambiguidade do conceito é tanto uma vantagem quanto uma desvantagem. É uma desvantagem, pois expõe o conceito a múltiplas interpretações, permitindo que seja usado para diferentes propósitos por diferentes pesquisadores e planejadores territoriais. Ao mesmo tempo, é uma vantagem, pois isso facilita a sua aceitação política universal, especialmente porque provoca uma imagem positiva (DAVOUDI, 2007).

\subsection{REDE URBANA E CIDADE MÉDIA}

O policentrismo também está diretamente ligado à noção de rede urbana, de forma que quanto maior a policentricidade da região, melhor articulada estará sua rede urbana. Esta, conforme Correa (2017, p. 29) "é entendida como o conjunto de centros, hierarquizados ou funcionalmente especializados e com diversas dimensões demográficas, articulados entre si, via fluxos materiais e não materiais".

É no contexto das redes urbanas que se situam as cidades médias, que possuem o importante papel de intermediação no âmbito das redes urbanas. A noção de cidade média só pode ser compreendida como parte integrante de uma rede urbana, uma vez que é de natureza relacional e envolve relações com centros menores e maiores do que ela (CORRÊA, 2017).

Diante disso, as cidades médias possuem papel estratégico na rede urbana por serem referência para pequenos aglomerados urbanos e o meio rural de seu entorno, ao mesmo tempo que mantém relações com centros urbanos maiores e mais importantes hierarquicamente. Sendo assim, são importantes nós de redes urbanas em diferentes escalas regionais. Desse modo, além de serem necessárias, por parte dos pesquisadores, análises multiescalares, também se torna importante a realização de estudos dando enfoque para as cidades médias. (OLIVEIRA; SOARES, 2014)

0 termo cidade média, apesar de ser amplamente utilizado em trabalhos acadêmicos e técnicos, carece de uma definição precisa. Também são utilizados como sinônimos os termos cidade intermediária, cidade regional, cidade de porte médio ou centro regional, igualmente sem grande precisão (OLIVEIRA; SOARES, 2014). Conforme Corrêa (2007, p. 23) o conceito é "uma expressão vaga, aberta a múltiplos significados e impregnada do 
idealismo que a concebe como um ideal a ser alcançado, apresentando as vantagens de uma pequena cidade sem ter, contudo, as desvantagens das grandes".

Uma cidade média possui população acima da média regional, exerce influência em uma determinada subregião, com funções que a fazem assumir o papel de polo regional na hierarquia urbana, fornecendo o consumo produtivo e coletivo da sua região de influência. (DEUS, 2004, p. 89-90) Nesse sentido, ela pode ser definida por características demográficas, funcionais e seu papel de intermediação entre centros menores e maiores. (BRANCO, 2006)

Há um consenso de que o tamanho populacional de uma cidade média não é uma característica determinante da mesma (BRANCO, 2006). Apesar disso, Amorim e Serra (2001, p. 3) apontam que deve ser considerada uma faixa de tamanho populacional, não para definição, mas para investigação. Mais recentemente, o IBGE tem adotado como critério exploratório inicial essa classificação tipológica para os casos de núcleos urbanos com população residente na faixa de 100 a 500 mil habitantes. (RAMOS, MATOS e GARCIA, 2011)

Soares (2005) afirma que apesar de serem identificadas de forma generalizada como médias, as cidades são singulares, com diferentes formas de relações na rede urbana e com seu entorno regional. Por isso, a autora propõe que as cidades médias sejam estudadas considerando as possibilidades de circulação de pessoas, mercadorias, informações e valores, já que são esses elementos que intensificam as relações entre as cidades e suas regiões e, ao mesmo tempo, diferenciam umas das outras.

Por fim, parece não haver dúvidas de que, independentemente dos critérios de definição conceitual, as cidades médias têm-se apresentado como importantes espaços no âmbito das redes urbanas (RAMOS, MATOS e GARCIA, 2011).

\section{METODOLOGIA}

A abordagem metodológica deste estudo se consistiu inicialmente de uma revisão teórica e conceitual, por meio de pesquisa bibliográfica, para delimitar os conceitos de policentrismo, rede urbana, área urbana funcional e coesão territorial e gestão territorial, com destaque para a utilização de bibliografia estrangeira e brasileira. Com isso, foram realizadas discussões a partir desses conceitos, bem como de suas possíveis contribuições para a análise do desenvolvimento regional na Região dos Vales.

Utilizaremos como recorte espacial a Região dos Vales. Ela é definida como aquela que espacialmente engloba conjuntamente as delimitações políticas dos COREDEs do Vale do Rio Pardo e do Vale do Taquari, representando também a Região Funcional de Planejamento 2 do Estado do Rio Grande do Sul. A região está localizada na zona centro oriental do estado, onde se localizam os municípios de Santa Cruz do Sul e de Lajeado.

Em um segundo passo metodológico foram coletados dados secundários sobre a região, especialmente dados levantados pelo IBGE, através das bases de dados dos estudos Gestão do Território (2014), da REGIC (2007), REGIC (1993), REGIC (1987), e do Censo Demográfico (2010). Desse modo, também foi estabelecido um corte temporal de análise de 2007 a 2014.

Para um tratamento mais completo dos dados foram ainda selecionadas informações dos três estudos da REGIC, feitos pelo IBGE em 1987, 1993 e 2007, formando uma única tabela comparativa. Também foi realizada uma pesquisa mais aprofundada acerca das emancipações dos municípios da Região dos Vales, valendo-se de dados disponibilizados pelo Censo Demográfico de 2010, pelo IBGE Cidades e pela Federação das Associações dos Municípios do Rio Grande do Sul (FAMURS). Assim, buscou-se melhor entender as mudanças que a Região dos Vales experimentou em sua formação territorial e em sua rede urbana ao longo dos últimos trinta anos e qual foi a influência das emancipações municipais no recorte temporal de análise de 2007-2014.

Para entender a estrutura da rede urbana e a articulação do território regional, foram selecionados os dados da Gestão do Território de 2014. Esses dados se referem aos fluxos de gestão pública federal com origem e/ou destino para os municípios da Região dos Vales, bem como a intensidade de cada fluxo. Conforme o IBGE (2014), a origem e destino dos fluxos são arbitrários, uma vez que as ligações são, na prática de trabalho das instituições públicas selecionadas, realizadas em ambos os sentidos. Foram selecionadas instituições pertencentes aos 
poderes executivo e judiciário, sendo elas o Instituto Nacional do Seguro Social (INSS), o Ministério do Trabalho e Emprego, a Secretaria da Receita Federal, a Justiça Federal, os Tribunais Regionais Eleitorais, os Tribunais Regionais do Trabalho, e o IBGE. Ainda de acordo com IBGE (2014), também foi levada em consideração a localização de sedes dos órgãos da administração indireta monolocalizados, mas com atuação de alcance nacional, com dados relativos a esses órgãos levantados a partir de suas próprias páginas na Internet e em consultas diretas, realizadas por e-mail, durante o ano de 2013.

Além disso, foi pesquisada a quantidade e a especificação dos escritórios, repartições dos órgãos públicos estaduais de gestão do território presentes em cada município da Região dos Vales. Esses dados foram compilados a partir das próprias páginas das instituições estaduais na internet no ano de 2017 , sendo elas as Comarcas, o Departamento Autônomo de Estradas de Rodagem (DAER), a Coordenadoria Regional de Saúde (CRE), a Polícia Ambiental, o Corpo de Bombeiros, a Brigada Militar, a Polícia Civil, a Delegacia Polícia Civil Especializada, o Instituto de Previdência do Estado do Rio Grande do Sul (IPERGS) e o Centro de Registro de Veículos Automotores (CRVA) do Departamento Estadual de Trânsito (DETRAN).

Após, os dados foram interpretados com base no referencial teórico e conceitual adotado. Para isso, os dados foram sistematizados em tabelas e representados em mapas temáticos. Enquanto as tabelas foram configuradas e organizadas em softwares de edição de planilhas, como o Excel, os mapas temáticos foram elaborados através do uso de shapefiles disponibilizados pelo IBGE, editados em programas de georreferenciamento como o QGis e, por fim, finalizados e trabalhados livremente em programas de tratamento de imagens vetorizadas, como o Adobe Illustrator.

\section{RESULTADOS E DISCUSSÃO}

\subsection{CARACTERIZAÇÃO DA REGIÃO DOS VALES}

De acordo com IBGE (2010), a Região dos Vales possui população total de 745.864 habitantes o equivalente a $7 \%$ da população do estado do Rio Grande do Sul. Do total da população regional, $68 \%$ residem na área urbana e $32 \%$ na área rural. Apesar disso, dos 59 municípios da região, 35 apresentam mais de $50 \%$ da população residindo no meio rural. Seus municípios mais populosos e principais centros urbanos são Santa Cruz do Sul, com 118.374 habitantes, e Lajeado, com 71.445 habitantes, em 2010.

Com relação à estrutura econômica da região, o setor produtivo mais tradicional destaca as atividades de base agrícola, fundada em quatro produtos dominantes - fumo, milho, arroz e soja - com produção quase toda sustentada por pequenas propriedades rurais. No Vale do Rio Pardo, os principais segmentos são os produtos do fumo, nos quais a região é responsável por $90,24 \%$ da produção do Estado, e a fabricação de produtos alimentícios, com destaque para o abate e fabricação de produtos de carnes, representando $1,60 \%$ do total do Estado. Já o Vale do Taquari apresenta uma estrutura industrial mais diversificada, com destaque para a fabricação de produtos alimentícios, também com destaque para o abate e fabricação de produtos de carne, representando $13,08 \%$ do segmento no Estado, a fabricação de produtos de madeira, com 19,95\% do total do Estado, e a preparação de couro e artefatos de couro, com 10,32\%. (SEPLAN, 2015a)

A seguir, a Figura 1 apresenta os principais eixos rodoviários e a densidade demográfica de acordo com a Grade Estatística, elaborada pelo IBGE em 2016. Em relação aos principais eixos rodoviários, pode-se destacar a BR290, que atravessa o Estado de oeste a leste e alcança a região no município de Pantano do Sul e a BRS-287, que liga Lajeado à Santa Cruz do Sul e liga a BR-386 ao oeste do Estado. Estas rodovias recebem intenso tráfego de mercadorias e passageiros de outras regiões e até de países vizinhos, aproximam a região dos Vales, da Região Metropolitana de Porto Alegre (RMPA), e conectam as cidades médias de Santa Cruz do Sul e de Lajeado à capital gaúcha (SEPLAN, 2015a; SEPLAN, 2015b; SEPLAN, 2015c).

Além disso, Santa Cruz do Sul está conectada a BR-471, que é uma importante via de ligação dos municípios do Vale do Rio Pardo com o Porto de Rio Grande e com o extremo sul do Estado. Já o Vale do Taquari encontra-se conectado a uma das principais artérias de circulação do Estado, a BR-386, registrando fluxos importantes nessa 
direção. A BRS-453 possui importância por ligar a região à Bento Gonçalves e Caxias do Sul e à BR-116. (SEPLAN, 2015a; SEPLAN, 2015b; SEPLAN, 2015c)

Figura 1 - Região dos Vales-RS: Densidade populacional e eixos viários

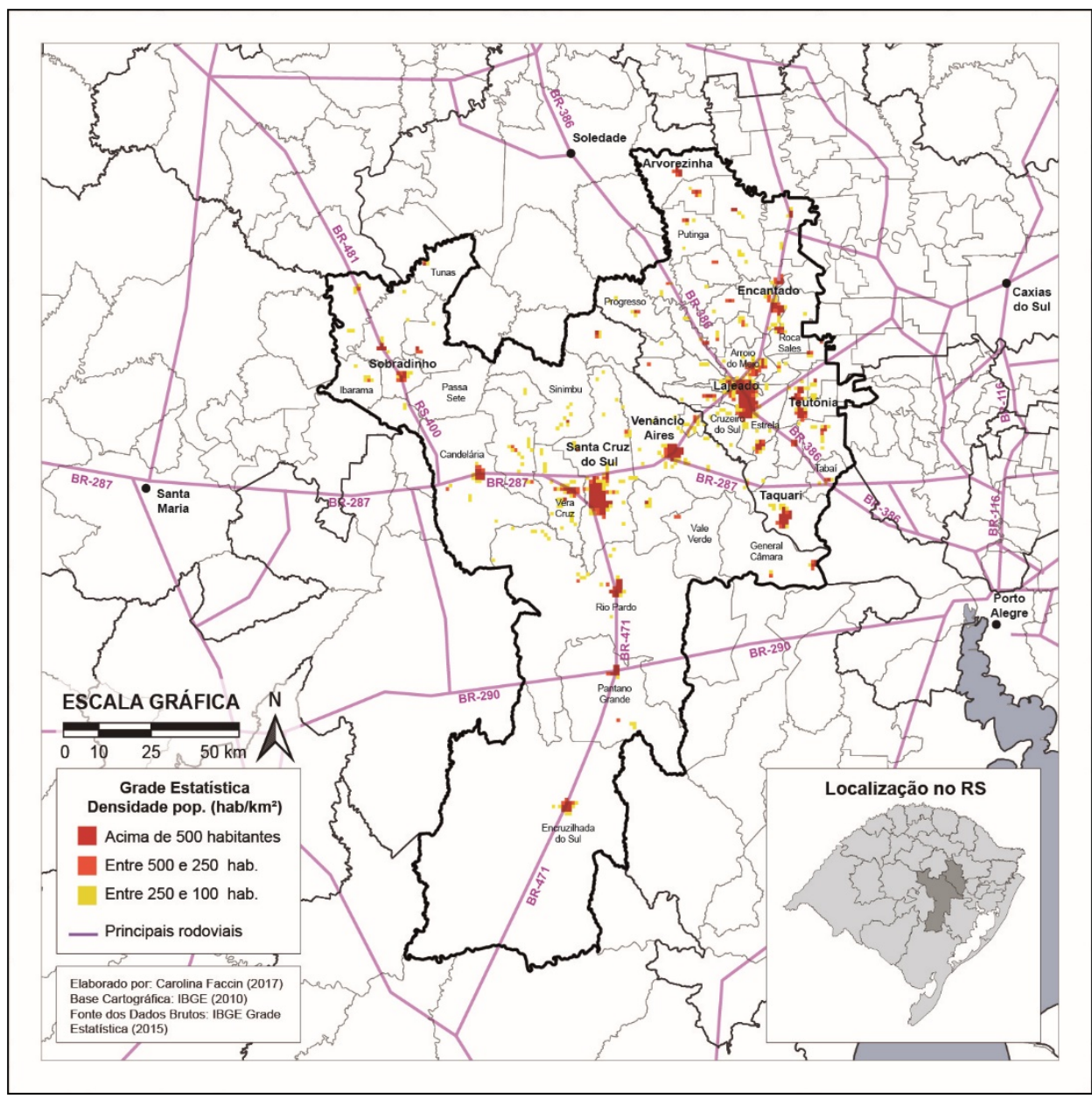

Fonte: Carolina Faccin, a partir de IBGE (2016)

Relativo à densidade demográfica, constata-se maiores aglomerações de pessoas na sub-região do Vale do Taquari, em comparação a sub-região do Vale do Rio Pardo. Enquanto a primeira possui densidade populacional de $67,9 \mathrm{hab} / \mathrm{km}^{2}$, a segunda possui $32,7 \mathrm{hab} / \mathrm{km}^{2}$. Destaca-se a contiguidade dos centros urbanos dos municípios de Vera Cruz e Santa Cruz do Sul; de Lajeado, Estrela, Cruzeiro do Sul, Arroio do Meio e Santa Clara do Sul; e de Encantado, Roca Sales e Muçum.

Também na Figura 1 pode-se observar uma maior fragmentação municipal no Vale do Taquari, em comparação ao Vale do Rio Pardo. Enquanto o primeiro possui 36 municípios e área territorial de $4.826,7 \mathrm{~km}^{2}$, o segundo possui 23 municípios e uma área de 13.171,7 km². Essa maior fragmentação municipal do Vale do Taquari, em comparação ao Vale do Rio Pardo, pode ser explicada devido a um intenso processo de emancipações municipais ocorrido entre os anos 1988 e 2001.

\subsection{EMANCIPAÇÕES E MUDANÇAS NA ESTRUTURA DA REGIÃO DOS VALES}

Segundo Magalhães (2008), após o período militar no Brasil houve um significativo incremento no número de municípios no país. Entre 1984 e 2000 houve a instalação de 1.405 novos municípios no país, principalmente nas regiões Sul e Nordeste. Essa forte onda de emancipações municipais, portanto, não ocorreu somente no Vale do Taquari. As principais causas das emancipações no Brasil foram estudadas por Bremaeker (1993), que realizou uma pesquisa através de envio de questionários abertos aos prefeitos dos novos municípios em 1992. Ele obteve 62 respostas, que representavam uma amostra de 12,4\% do total. Também, das 62 respostas, 24 
vieram do Sul do Brasil. As principais alegações eram a do descaso por parte da administração do município de origem (62,9\%); existência de forte atividade econômica local $(27,4 \%)$ e grande extensão territorial do município de origem (24,2\%). Para o autor, as justificativas de descaso por parte da administração do município de origem e sua grande extensão territorial estão fortemente relacionadas, pois quanto mais distante estiver a população da sede do município mais difícil será atender aos seus anseios.

O estado do Rio Grande do Sul também passou por um processo intenso de emancipações municipais. Conforme a FAMURS (2011), no ano de 1981 o estado possuía 232 municípios e, em 1996, alcançou o número de 496 municípios. Ou seja, em um período de 15 anos, houve um aumento de $114 \%$ em relação ao número de municípios. Atualmente, conforme IBGE (2017), após emancipação de um distrito de Bento Gonçalves em 2013, o estado conta com 497 municípios.

Já na Região dos Vales, até o ano de 1964, o Vale do Taquari possuía 14 municípios, enquanto o Vale do Rio Pardo possuía 10. Entre os anos de 1981 e 1996, foram criados 22 municípios na primeira região e 13 na segunda, havendo um aumento, respectivamente, de $157 \%$ e $130 \%$. Ou seja, um crescimento maior que a média do estado. Destaca-se o Vale do Taquari, com um aumento superior ao Vale do Rio Pardo, apesar de possuir significantemente menor extensão territorial (FAMURS, 2011). Também é possível observar, através do Quadro 1 , o aumento no número de municípios da Região dos Vales nesse período. Esse processo intenso de emancipações municipais resultou numa nova configuração territorial com decorrentes reflexos na dinâmica de constituição, estrutura e funcionamento da rede urbana regional.

Em relação à rede urbana regional, o Quadro 1 apresenta dados referentes à hierarquia urbana, bem como à evolução e às mudanças na estrutura da rede urbana da Região dos Vales, segundo os estudos da REGIC de 2007, REGIC de 1993 e REGIC de 1987, elaborados pelo IBGE.

Quadro 1 - Centralidade da rede urbana na região dos Vales: um quadro comparativo de 1987 a 2007

\begin{tabular}{|c|c|c|c|c|c|}
\hline \multicolumn{2}{|c|}{ REGIC (1987) } & \multicolumn{2}{|c|}{ REGIC (1993) } & \multicolumn{2}{|c|}{ RECIG (2007) } \\
\hline $\begin{array}{c}\text { Nivel de } \\
\text { Centralidade }\end{array}$ & Cidades & $\begin{array}{c}\text { Nivel de } \\
\text { Centralidade }\end{array}$ & Cidades & $\begin{array}{c}\text { Nível de } \\
\text { Centralidade }\end{array}$ & Cidades \\
\hline $\begin{array}{c}\text { Metrópole } \\
\text { regional }\end{array}$ & Porto Alegre & Máximo & Porto Alegre & Metrópole & Porto Alegre \\
\hline \multirow{2}{*}{$\begin{array}{l}\text { Centro Sub- } \\
\text { regional }\end{array}$} & Lajeado-Estrela & \multirow{2}{*}{ Forte $p /$ médio } & Santa Cruz do Sul & \multirow{2}{*}{$\begin{array}{c}\text { Centro } \\
\text { Subregional A }\end{array}$} & Santa Cruz do Sul \\
\hline & Santa Cruz do Sul & & Lajeado & & Lajeado \\
\hline \multirow{9}{*}{ Centro de Zona } & \multirow{2}{*}{ Taquari } & Médio & Estrela & \multirow{3}{*}{ Centro de Zona A } & Estrela \\
\hline & & \multirow{2}{*}{ Médio $\mathrm{p} /$ fraco } & Encantado & & Encantado \\
\hline & \multirow{2}{*}{ Encantado } & & Sobradinho & & Venâncio Aires \\
\hline & & \multirow{6}{*}{ Fraco } & \multirow{6}{*}{ Venâncio Aires } & \multirow{6}{*}{ Centro de Zona B } & Arvorezinha \\
\hline & \multirow{2}{*}{ Sobradinho } & & & & Sinimbu \\
\hline & & & & & Sobradinho \\
\hline & \multirow{3}{*}{ Rio Pardo } & & & & Teutônia \\
\hline & & & & & Arroio do Meio \\
\hline & & & & & Muçum \\
\hline $\begin{array}{c}\text { Municípios } \\
\text { Subordinados }\end{array}$ & $\begin{array}{c}\text { Restante dos } \\
\text { municípios (25) }\end{array}$ & Muito fraco & $\begin{array}{c}\text { Restante dos } \\
\text { municípios (38) }\end{array}$ & Centro Local & $\begin{array}{l}\text { Restante dos } \\
\text { municípios (48) }\end{array}$ \\
\hline
\end{tabular}

Fonte: Carolina Faccin, a partir de IBGE (2007), IBGE (1993) e IBGE (1987).

Os dados referentes à REGIC de 2007 apresentam a Região dos Vales com dois Centros Sub-Regionais (Santa Cruz do Sul e Lajeado), três Centros de Zona A (Venâncio Aires, Estrela e Encantado), seis Centros de Zona B (Sobradinho, Sinimbu, Arvorezinha, Muçum, Teutônia e Arroio do Meio) e os demais 48 municípios classificados como Centros Locais. (IBGE, 2007)

Os dados da REGIC de 1993 mostram que a rede urbana da Região dos Vales possuía dois municípios classificados com centralidade "forte para médio" (Santa Cruz do Sul e Lajeado), um município "médio" (Estrela) e dois municípios no nível "médio para fraco" (Sobradinho e Encantado). Os 38 restantes municípios se 
configuravam no nível "muito fraco" (IBGE, 1993). Em comparação ao ano de 2007, Estrela possuía maior centralidade na rede urbana da Região.

Já em 1987, de acordo com a REGIC de 1987, a Região dos Vales apresentava duas Capitais Regionais (Santa Cruz do Sul e Lajeado-Estrela), um Centro Subregional (Rio Pardo) e três Centros de Zona (Sobradinho, Taquari e Encantado). Os 25 restantes municípios foram classificados como Municípios Subordinados. (IBGE, 1987) Diferentemente dos anos de 1993 e 2007, Lajeado e Estrela são representados como uma só cidade, de mesmo nível que Santa Cruz do Sul.

Tais mudanças revelam a intensidade e a complexidade do processo de urbanização das cidades de Santa Cruz do Sul e de Lajeado no contexto da região, ampliando o seu grau de centralidade e seu poder de influência econômica e de serviços em relação às demais cidades. Também se observa a ampliação na rede urbana do número de pequenas cidades que passaram a desempenhar o papel de centros urbanos locais no contexto da região, cuja dinâmica de crescimento se vincula diretamente à economia agrícola, predominante nos pequenos municípios da região.

\subsection{GESTÃO PÚBLICA DO TERRITÓRIO}

Atualmente, o Estado é uma das instituições com maior poder estruturador, atuando através de organismos públicos criados para atender a população, levantar dados e informações e recolher tributos. Desta forma, o tema das redes e fluxos de gestão do território possui grande força de organização espacial (IBGE, 2014). A Figura 2 apresenta os fluxos de gestão pública federal com origem e/ou destino para os municípios da Região dos Vales, bem como a intensidade de cada fluxo.

Figura 2 - Região dos Vales-RS: Fluxos de gestão pública federal

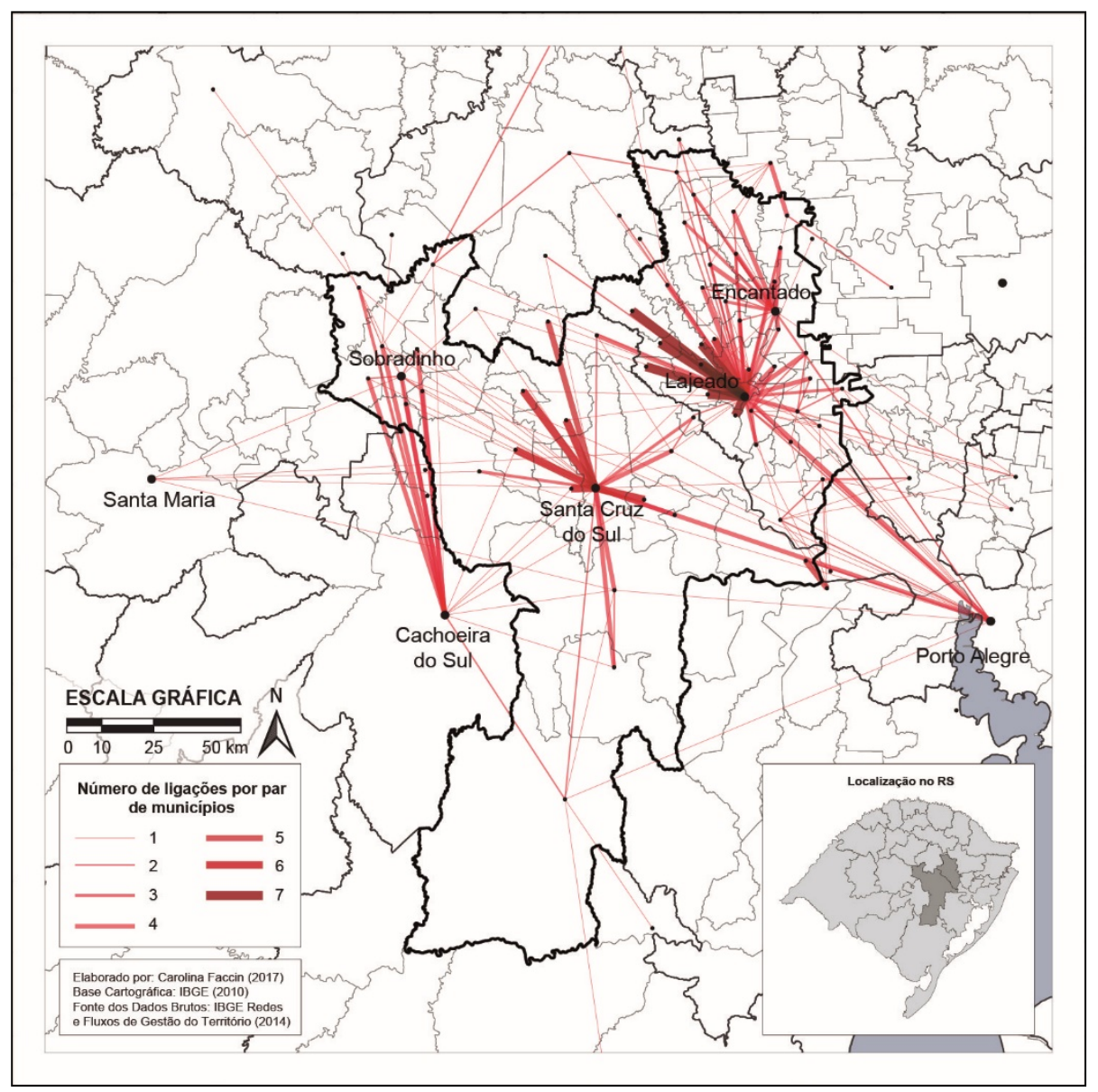

Fonte: Carolina Faccin, a partir de IBGE (2014). 
Nos municípios, é nas cidades que tal dinâmica se desenvolve de modo mais intenso. É visível quatro municípios, ou mais exatamente, quatro cidades que se sobressaem e polarizam os municípios de seus entornos. A primeira é Lajeado, que possui 160 ligações com 48 municípios de dentro e fora da Região dos Vales; em segundo lugar, Santa Cruz do Sul, que possui 80 ligações com 27 municípios diferentes. Também se destacam a cidade de Encantado, com 43 ligações com 27 municípios de seu entorno, e a de Sobradinho, com 13 ligações com 8 municípios diferentes. Além disso, a cidade de Sobradinho e os municípios de seu entorno possuem fortes ligações com Cachoeira do Sul, e Porto Alegre possuem influência na região, tendo fortes ligações com Santa Cruz do Sul e Lajeado (IBGE, 2014).

Quadro 2 - Região dos Vales-RS: Fluxos de gestão pública federal

\begin{tabular}{|c|c|c|c|c|c|}
\hline \multicolumn{6}{|c|}{ Quantidade de ligações entre um par de municípios } \\
\hline Município de origem & Município de destino & Quant. & Município de origem & Município de destino & Quant. \\
\hline Canudos do Vale & Lajeado & 7 & Doutor Ricardo & Encantado & 4 \\
\hline Cruzeiro do Sul & Lajeado & 7 & Mucum & Encantado & 4 \\
\hline Forquetinha & Lajeado & 7 & Relvado & Encantado & 4 \\
\hline Marques de Souza & Lajeado & 7 & Roca Sales & Encantado & 4 \\
\hline Progresso & Lajeado & 7 & Vespasiano Correa & Encantado & 4 \\
\hline Santa Clara do Sul & Lajeado & 7 & Dois Lajeados & Guaporé & 4 \\
\hline Sério & Lajeado & 7 & Boqueirão do Leão & Lajeado & 4 \\
\hline Arroio do Meio & Lajeado & 6 & Capitão & Lajeado & 4 \\
\hline Travesseiro & Lajeado & 6 & Colinas & Lajeado & 4 \\
\hline Herveiras & Santa Cruz do Sul & 6 & Coqueiro Baixo & Lajeado & 4 \\
\hline Passo do Sobrado & Santa Cruz do Sul & 6 & Estrela & Lajeado & 4 \\
\hline Sinimbu & Santa Cruz do Sul & 6 & Imigrante & Lajeado & 4 \\
\hline Vale do Sol & Santa Cruz do Sul & 6 & Pouso Novo & Lajeado & 4 \\
\hline Vera Cruz & Santa Cruz do Sul & 6 & Teutônia & Lajeado & 4 \\
\hline Gramado Xavier & Santa Cruz do Sul & 5 & Westfália & Lajeado & 4 \\
\hline General Câmara & São Jerônimo & 5 & Lajeado & Porto Alegre & 4 \\
\hline Arroio do Tigre & Cachoeira do Sul & 4 & Santa Cruz do Sul & Porto Alegre & 4 \\
\hline Ibarama & Cachoeira do Sul & 4 & Pantano Grande & Santa Cruz do Sul & 4 \\
\hline Lagoa Bonita do Sul & Cachoeira do Sul & 4 & Rio Pardo & Santa Cruz do Sul & 4 \\
\hline Passa Sete & Cachoeira do Sul & 4 & Vale Verde & Santa Cruz do Sul & 4 \\
\hline Segredo & Cachoeira do Sul & 4 & Venâncio Aires & Santa Cruz do Sul & 4 \\
\hline Sobradinho & Cachoeira do Sul & 4 & \multirow{2}{*}{\multicolumn{3}{|c|}{$\begin{array}{c}\text { Legenda: Municípios do Vale do Rio Pardo e do Vale do } \\
\text { Taquari }\end{array}$}} \\
\hline Anta Gorda & Encantado & 4 & & & \\
\hline
\end{tabular}

Fonte: Carolina Faccin e Nicolas Giacometti, a partir de IBGE (2014)

0 Quadro 2, por sua vez, dá ênfase e melhor detalhadamente os dados representados na Figura 2. Ele apresenta, no entanto, um recorte dos dados totais, mostrando os pares de municípios com 4 ou mais ligações, enquanto na Figura 2 estão representados todos os dados, sem exceções.

Já a Figura 3 apresenta o total de centros públicos estaduais de gestão do território presentes em cada município da Região dos Vales. Podemos destacar as cidades de Santa Cruz do Sul, que possui 10 instituições estaduais no município; Lajeado, com 9 instituições estaduais; Estrela, com 8 instituições; e Rio Pardo com 7. 
Figura 3 - Centros de gestão pública estadual

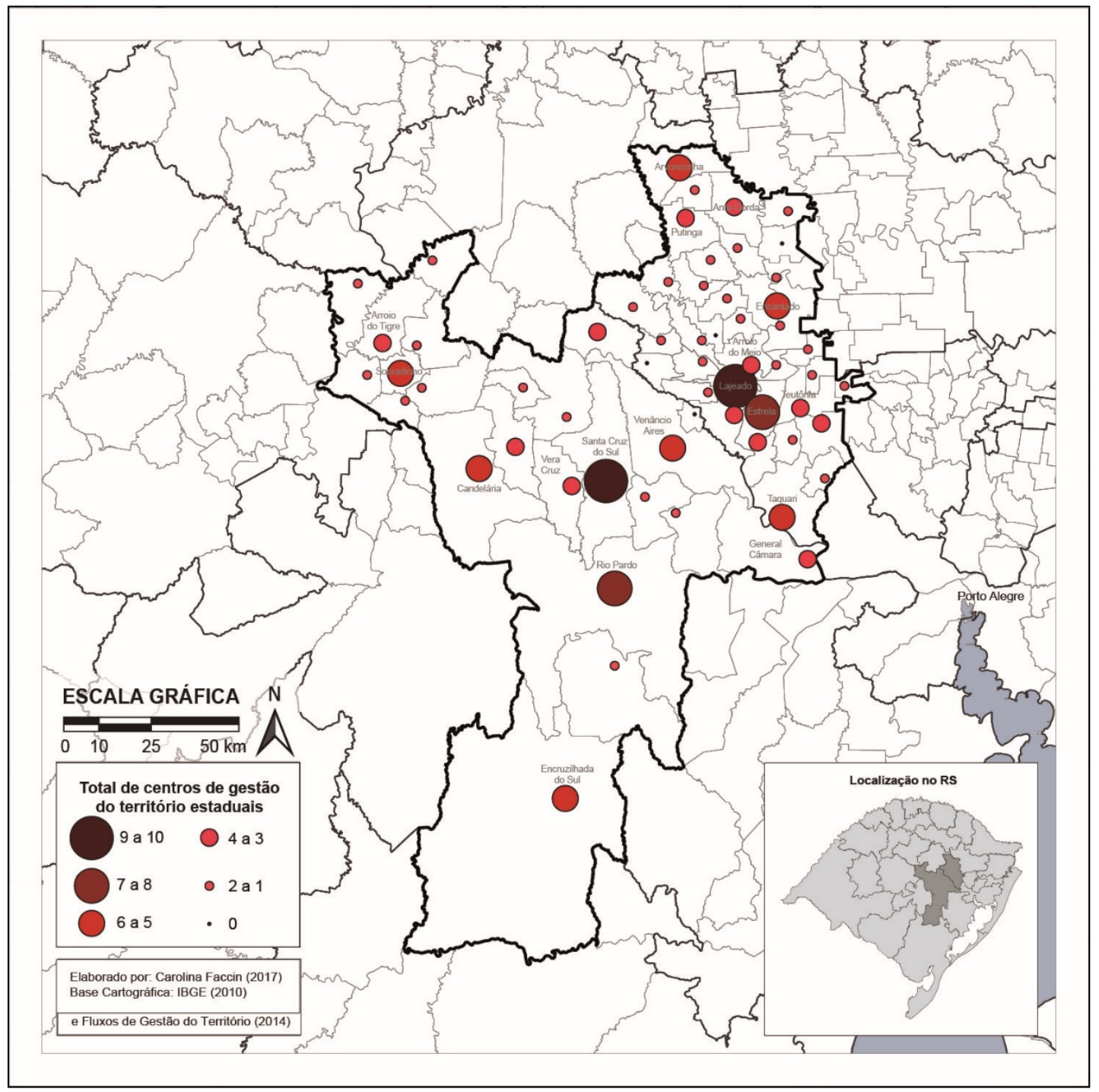

Fonte: Carolina Faccin, a partir de Nicolas Giacometti (2017).

Cabe também destacar os municípios de Sobradinho, Candelária, Encruzilhada do Sul, Venâncio Aires, Taquari, Encantado e Arvorezinha por possuírem de 6 a 5 centros de gestão estadual em seu território. Os municípios de Mato Leitão, Sério, Travesseiro e Vespasiano Correa não possuem nenhuma das instituições estaduais pesquisadas em seu território.

Por fim, no Quadro 3, são apresentados, para os municípios que apresentam 04 centros de gestão pública do território ou mais, quais são os órgãos públicos estaduais que estão presentes em cada município. Podemos observar que Lajeado não possui sedes da CRE e da Polícia Ambiental, mas Estrela, município contíguo ao de Lajeado, possui uma de cada. Do mesmo modo, Santa Cruz do Sul não possui sedes do IPE-RS e da Polícia Ambiental, ao contrário de Rio Pardo. Vera Cruz, por ser um município com pequeno centro urbano, e dada sua proximidade geográfica de Santa Cruz do Sul, não necessita de tantos centros de gestão estadual, já que a população pode facilmente se deslocar à Santa Cruz do Sul para suprir suas demandas por serviço público. 
Quadro 3 - Centros de gestão pública estadual

\begin{tabular}{|c|c|c|c|c|c|c|c|c|c|c|c|c|}
\hline & $\begin{array}{l}\text { n } \\
\frac{1}{0} \\
\frac{1}{\alpha} \\
\frac{\mathbf{c}}{8} \\
0\end{array}$ & 䈬 & $\begin{array}{l}0 \\
\frac{0}{0}\end{array}$ & 崩 & 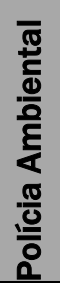 & $\begin{array}{l}\text { 을 } \\
\overline{0} \\
\text { है } \\
\text { है }\end{array}$ & 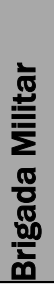 & $\begin{array}{l}\bar{\sum} \\
\overline{0} \\
\frac{\pi}{0} \\
\frac{0}{0} \\
\Omega\end{array}$ & 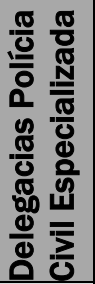 & 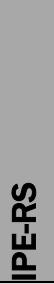 & 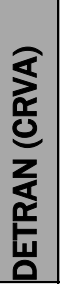 & 훙 \\
\hline Lajeado & 1 & 1 & 1 & - & - & 1 & 1 & 1 & 1 & 1 & 1 & 9 \\
\hline Santa Cruz do Sul & 1 & 1 & 1 & 1 & - & 1 & 1 & 1 & 1 & - & 1 & 9 \\
\hline Estrela & 1 & - & - & 1 & 1 & 1 & 1 & 1 & - & 1 & 1 & 8 \\
\hline Rio Pardo & 1 & - & - & - & 1 & 1 & 1 & 1 & - & 1 & 1 & 7 \\
\hline Encruzilhada do Sul & 1 & - & - & - & - & 1 & 1 & 1 & - & 1 & 1 & 6 \\
\hline Venâncio Aires & 1 & - & - & - & - & 1 & 1 & 1 & - & 1 & 1 & 6 \\
\hline Arvorezinha & 1 & - & - & - & - & - & 1 & 1 & - & 1 & 1 & 5 \\
\hline Candelária & 1 & - & - & - & - & - & 1 & 1 & - & 1 & 1 & 5 \\
\hline Encantado & 1 & - & - & - & - & - & 1 & 1 & - & 1 & 1 & 5 \\
\hline Sobradinho & 1 & - & - & - & - & - & 1 & 1 & - & 1 & 1 & 5 \\
\hline Arroio do Tigre & 1 & - & - & - & - & - & 1 & 1 & - & - & 1 & 4 \\
\hline Taquari & 1 & - & - & - & - & - & - & 1 & - & 1 & 1 & 4 \\
\hline Vera Cruz & 1 & - & - & - & - & - & 1 & 1 & - & - & 1 & 4 \\
\hline
\end{tabular}

Fonte: Nicolas Giacometti (2017)

Os dados igualmente mostram uma maior concentração dos órgãos públicos estaduais nas cidades médias de Santa Cruz do Sul e Lajeado, que a partir dessas cidades acabam ofertando serviços e atendendo a população não apenas desses dois municípios, mas do conjunto da região. Tal condição e característica reforçam o papel de comando que tais cidades apresentam no conjunto da rede urbana regional.

\section{CONCLUSÃO}

Esse estudo exploratório sobre distribuição espacial das estruturas de gestão do território, na Região dos Vales, evidencia um incipiente e desigual conteúdo policêntrico no território regional através dos fluxos de gestão pública federal entre os municípios e à quantidade de centros de gestão pública estadual presentes na região, que apontam a influência das cidades de Santa Cruz do Sul e Lajeado na dinâmica territorial e na rede urbana regional.

Podemos observar o expressivo grau de centralidade urbana das cidades médias de Santa Cruz do Sul e Lajeado, que possuem forte vínculo com os municípios de seu entorno, exercendo papel intermediário entre as cidades menores da sua região, e de suas áreas rurais com a metrópole de Porto Alegre. Bem como, observam-se estreitos vínculos entre elas, dada a concentração de órgãos públicos, atividades de comércio e serviço. Destacase o papel importante de órgãos do Estado brasileiro em sua instância federal, bem como estruturas públicas estaduais que acabam ofertando serviços que atendem uma população localizada não só dentro como além dos limites administrativos municipais de Santa Cruz do Sul e Lajeado.

Observa-se no conjunto do território regional um incipiente processo de policentrismo, com fluxos mais dinâmicos e intensos, concentrados, sobretudo nas cidades médias de Santa Cruz do Sul e Lajeado e nas cidades de seu entorno próximo, reforçando o dinamismo dessas áreas na rede urbana regional. Lajeado, no entanto, possui ligação com uma maior quantidade de municípios, e um processo policêntrico aparentemente mais desenvolvido. Isso se deve à maior fragmentação da região do Vale do Taquari e por ela ter passado por um processo emancipatório mais intenso, em comparação à Santa Cruz do Sul e ao Vale do Rio Pardo que, por sua vez, possui municípios com maior extensão territorial. Pode-se destacar também a cidade de Estrela que junto à Lajeado, e por serem cidades com centro urbano contíguo, polarizam os municípios de seu entorno. Também, a cidade de Encantado, classificada assim como Estrela como Centro de Zona A, pela REGIC (2007), exerce alto grau de centralidade urbana de municípios da sua área próxima. Venâncio Aires, Sobradinho e Rio Pardo também possuem importância por polarizarem municípios e áreas rurais próximas às suas cidades. Por último, 
Cachoeira do Sul, mesmo estando fora da Região dos Vales, demonstra influência na região, por ter ligações relativas aos fluxos de gestão pública federal com Sobradinho e os municípios adjacentes.

Os resultados desse estudo exploratório, baseados na análise de dados da Gestão do Território (2014) e da REGIC (2007), organizados pelo IBGE, são um passo inicial importante, mas ainda não nos permitem compreender em profundidade a dinâmica territorial regional e a organização e funcionamento da rede urbana regional. Para tanto, ainda falta concluir os demais estudos, já iniciados no âmbito do GEPEUR - Grupo de Pesquisa e Estudos Urbanos e Regionais, incorporando também a coleta de dados acerca dos fluxos de gestão do território entre empresas privadas, bem como dos fluxos de migração, deslocamentos pendulares para trabalho e estudo, informações e capital.

Por fim, pensamos que a perspectiva de análise que o conceito policentrismo oferece, seja através de dados referentes aos fluxos de gestão do território ou de outros fluxos que circulam pelo território, é relevante para que se possa melhor diagnosticar a dinâmica territorial e pensar estratégias de desenvolvimento na escala regional. 0 policentrismo possibilita que evitemos um olhar segmentado e fragmentado do território e da dinâmica espacial, bem como oportuniza uma melhor observação e compreensão dos vários fluxos que circulam e conectam espaços do território em diferentes níveis escalares.

\section{REFERÊNCIAS}

AMORIM F, O.; SERRA, R. V. Evolução e perspectivas do papel das cidades médias no planejamento urbano e regional. In: ANDRADE, T. A., SERRA, R. V. (Org.). Cidades médias brasileiras. Rio de Janeiro: IPEA, 2001. p. 1-34

BRANCO, Maria Luisa Castello. As cidades médias no Brasil. In: SPÓSITO, Eliseu Savério; SPÓSITO, Maria Encarnação Beltrão; SOBARZO, Oscar. (Orgs.). Cidades médias: produção do espaço urbano regional. São Paulo: Expressão Popular, 2006. p. 245277

BREMAEKER, François E. J. Os novos municípios: surgimento, problemas e soluções. Revista de Administração Municipal. v. 40. n. 206. p. 88-99. jan/mar. 1993.

CAÑIZARES, María del Carmen. Los cambios y las estrategias territoriales: Hacía una correcta ordenación del territorio en Castilla-La Mancha. Biblio 3W. Revista Bibliográfica de Geografía y Ciencias Sociales, Barcelona, v. XIII, n. 704, 10 de febrero de 2007. <http://www.ub.edu/geocrit/b3w-704.htm>. Acesso em 5 mar. 2018.

CARMO, Renato Miguel do. Da escala ao território: para uma reflexão crítica do policentrismo. Análise Social, vol. XLIII, n 4, 2008, pg 775-793.

CORRÊA, Roberto Lobato. Construindo o conceito de cidade média. In: SPOSITO, M. E. B. (Org.). Cidades médias: espaços em transição. São Paulo: Expressão Popular, 2007. p. 23-33.

. A rede urbana e a cidade média. p. 29-38. In: SILVA, W. R.; SPOSITO, M. E. Perspectivas da urbanização: reestruturação urbana e das cidades. Rio de Janeiro: Consequência Editora, 2017. 1. ed. 270 p.

DAVOUDI, S. Polycentricity: Panacea or pipedream? In: CATTAN, N. (Org.) Cities and networks in Europe. Montrouge, France: John Libbey Eurotext, p.65-73, 2007.

. Territorial cohesion, European social model and transnational cooperation. p. 269-282. In: J. Knieling \& F. Othengrafen (Eds.). Planning cultures in Europe. Decoding cultural phenomena in urban and regional planning. Aldershot: Ashgate, 2009. p. 269-279

DEUS, João Batista. As cidades médias na nova configuração territorial brasileira. Boletim Goiano de Geografia, Goiânia, v. 24, n. 1-2, p. 81-91. jan./jun. 2004.

ESPON. ESPON 111. Potentials for polycentric development in Europe. Project report. August, 2004. Disponível em: <https://www.espon. eu/export/sites/default/Documents/Projects/ESPON2006Projects/ThematicProjects/Polycentricity/fr1.1.1_revised-full.pdf>. Acesso em: 11 abr. 2017.

FAMURS (Federação das Associações dos Municípios do Rio Grande do Sul). Planilha de Relação de Municípios. 2011. Disponível em: <http://www.famurs.com.br/guiars>. Acesso em: 19 dez. 2017.

FONSECA, F. P.; RAMOS, R. A. R. Formas de cooperação interurbana: o caso da rede de cidades do quadrilátero urbano. Revista Portuguesa de Estudos Regionais, Portugal, n. 25-26, p. 37-54. 2011.

KLOOSTERMAN, R.C.; LAMBREGTS, B. Clustering of Economic Activities in Polycentric Urban Regions: The Case of the Randstad, Urban Studies, 38, pp.717-732, 2001.

IBGE (Instituto Brasileiro de Geografia e Estatística). Centros de Gestão do Território. Rio de Janeiro: IBGE, 2014. Disponível <http://www.ibge.gov.br/home/geociencias/geografia/redes_fluxos/gestao_do_territorio_2014/default.shtm?c=11>.

Acesso em: 10 dez. 2017. 
Censo Demográfico do Brasil. Rio Grande do Sul: IBGE, 2010. Disponível em:

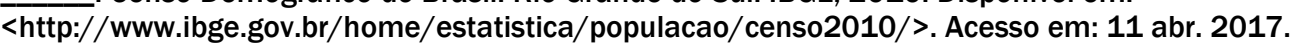

Grade Estatística. Rio de Janeiro: IBGE, 2016. Disponível: <https://mapas.ibge.gov.br/interativos/grade>. Acesso em: $10 \mathrm{dez} .2017$.

Regiões de Influência das Cidades. Rio de Janeiro: IBGE, 2007. Disponível em: <

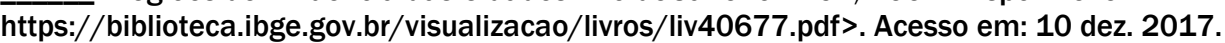

Regiões de Influência das Cidades. Rio de Janeiro: IBGE, 1993. Disponível em: <

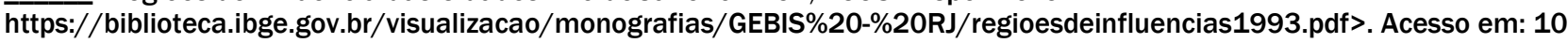
dez. 2017.

Regiões de Influência das Cidades. Rio de Janeiro: IBGE, 1987. Disponível em: < https://biblioteca.ibge.gov.br/visualizacao/monografias/GEBIS\%20-

\%20RJ/regioesdeinfluencia/Regioes\%20de\%20influencia\%20das\%20cidades_1987.pdf>. Acesso em: 10 dez. 2017.

IBGE Cidades: Pinto Bandeira. IBGE: 2017. Disponível em: < https://cidades.ibge.gov.br/brasil/rs/pintobandeira/historico>. Acesso em 21 fev. 2018.

MAGALHÃES, João Carlos. Emancipação política-administrativa de municípios no Brasil. 40 p. In: CARVALHO, A.; ALBUQUERQUE, C.; MOTA, J.; PIANCASTELLI, M. (Org.). Dinâmica dos Municípios. Brasília: IPEA, 2008. Disponível: <http://ipea.gov.br/agencia/images/stories/PDFs/livros/Capitulo1_30.pdf>. Acesso em: 06 jan. 2018.

MEIJERS, Evert. The notion of complementarity in urban networks: definition, value, measurement and development. 2006. Disponível em:

<https://www.researchgate.net/publication/242673823_The_notion_of_complementarity_in_urban_networks_definition_val ue_measurement_and_development>. Acesso em: 5 mar. 2018.

Polycentric Urban Regions and the Quest for Synergy: Is a Network of Cities More than the Sum of the Parts?, Urban Studies, v. 42, n. 4, p. 765-781, abr. 2005. Disponivel em:

<http://journals.sagepub.com/doi/abs/10.1080/00420980500060384>. Acesso em 5 mar. 2018.

MOURA, R.; WERNECK, D. Z. Rede, hierarquia e região de influência das cidades: um foco sobre a Região Sul. Revista Paranaense Desenvolvimento, Curitiba, n.100, p.27-57, jan/jun. 2001.

OLIVEIRA, H. C. M. de; SOARES, B. R. Cidade média: apontamentos metodológicos e tipologia. Caminhos de Geografia, Uberlândia, v. 15, n. 1, p. 119-133, dez. 2014.

RAMOS, E. F.; MATOS, R. E. S.; GARCIA, R. A. As cidades médias como nódulos de equilíbrio da rede de cidades. Revista Paranaense de Desenvolvimento, Curitiba, n. 121, p. 41-63, jul./dez. 2011.

SEPLAN (Secretaria do Planejamento, Mobilidade e Desenvolvimento Regional). Perfis Socioeconômicos por Regiões Funcionais de Planejamento. p. 25-30. Porto Alegre: SEPLAN, 2015a. Disponível em: <http://planejamento.rs.gov.br/upload/arquivos/201512/15134058-20150319163519perfis-todos.pdf >. Acesso em: 10 dez. 2017.

Perfil Socioeconômico COREDE Vale do Rio Pardo. Porto Alegre: SEPLAN, 2015b. Disponível em: < http://planejamento.rs.gov.br/perfis-regionais>. Acesso em: 19 dez. 2017.

Perfil Socioeconômico COREDE Vale do Taquari. Porto Alegre: SEPLAN, 2015c. Disponível em: < http://planejamento.rs.gov.br/perfis-regionais>. Acesso em: 19 dez. 2017.

SOARES, Beatriz Ribeiro. Cidades médias: uma revisão bibliográfica. In: ALVES, A. F.; FLÁVIO, L. C.; SANTOS, R. A. (Org.). Espaço e território: interpretações e perspectivas do desenvolvimento. Francisco Beltrão: UNIOESTE, 2005. p. 273-285. 